\title{
Estimation of coda $Q$ for the eastern Indian craton
}

\author{
Koushik Biswas ${ }^{1} *_{\odot}$, Prantik Mandal ${ }^{2}$ and Prosanta Kumar Khan ${ }^{3}$ \\ ${ }^{1}$ Oil and Natural Gas Corporation Limited, Dehradun, Uttarakhand 248 195, India. \\ ${ }^{2}$ National Geophysical Research Institute (CSIR), Uppal Road, Hyderabad 500 007, India. \\ ${ }^{3}$ Indian School of Mines (IIT), Dhanbad, Jharkhand 826004 , India. \\ *Corresponding author. e-mail: koushik.biswas59@gmail.com
}

MS received 1 May 2018; revised 25 September 2018; accepted 1 December 2018; published online 11 April 2019

We herein present new frequency-dependent coda- $Q\left(Q_{\mathrm{c}}\right)$ relations $\left(Q_{\mathrm{c}}=Q_{0} f^{n}\right)$ (frequency ranges between 2 and $18 \mathrm{~Hz}$ ) for three regions of the eastern Indian craton (EIC), viz., the Singhbhum Odisha craton (SOC) and the Eastern Ghat mobile belt (EGMB), comprising the Mahanadi basin and the Chotanagpur granitic gneissic terrain (CGGT). The frequency-dependent coda- $Q_{\mathrm{c}}$ relations are obtained through the single backscattering model for coda waves $\left(Q_{\mathrm{c}}\right)$ of local earthquakes which are recorded on 15 three-component broadband seismograph stations in the regions. In this work, we pay special attention to test the lapse time $\left(t_{\mathrm{L}}\right)$ dependency of coda- $Q\left(Q_{\mathrm{c}}\right)$ estimates for the three regions. Lapse time signifies the sample area of the coda wave of the study region. Generally, the sample area increases with lapse time. To test the lapse time $\left(t_{\mathrm{L}}\right)$ dependency, nine different lapse time windows $\left(t_{\mathrm{L}}\right)$ from 10 to $90 \mathrm{~s}$ with $10 \mathrm{~s}$ interval are considered. On the ground of estimated poor correlation coefficients, only six lapse time windows $\left(t_{\mathrm{L}}\right)$ from 40 to $90 \mathrm{~s}$ with $10 \mathrm{~s}$ interval are considered. Our results suggest more heterogeneity in EGMB than that of the SOC and CGGT region. Estimates of $Q_{0}$ and $n$ for the three regions of EIC (SOC, EGMB and CGGT) are found to be consistent with the results of $Q_{0}$ and $n$ for mildly active less heterogeneous seismic zones in different parts of the world. By assuming entirely intrinsic attenuation characteristics, actual hazard parameters, i.e., extinction distance and anelastic attenuation coefficients are also computed for the three regions. The extinction distance $\left(L_{\mathrm{e}}\right)$ provides an idea of the distribution of scatterers in the lithosphere and anelastic attenuation coefficients signify the anelasticity of the medium, i.e., fluid movement and grain distribution. The estimate of extinction distance and attenuation coefficients suggests that for all three study regions, the upper mantle is relatively less heterogeneous and attenuation below $110-126 \mathrm{~km}$ depth is also comparatively lower. Coda $Q$ indicates the degree of fracture and heterogeneity in the lithosphere related to seismicity. A higher estimate of $Q_{0}$ values in the Archaean SOC region and the Proterozoic CGGT region is found when compared with that of the sedimentary-rich EGMB. It can be inferred that seismically less active cratons in general comprise high $Q_{0}$ values, whereas the sedimentary-rich EGMB is more attenuative, characterised by a low coda $Q_{0}$ value. Moreover, it is found that the estimated $Q_{0}$ values for CGGT region are a little bit higher than that for the SOC region. This can be explained as a comparatively less disturbed and less heterogonous land mass that is present in the CGGT region as compared to the SOC region, which comprises different minerals, ore bodies, fault scarps and shear zones. The developed $Q_{\mathrm{c}}$ relation for the EIC region could be useful for the study of hazards and ground motion prediction.

Keywords. Attenuation; $Q$-value; lapse times; eastern Indian craton. 


\section{Introduction}

Some parts of the Eastern Indian craton are experiencing small to moderate size earthquakes, though it comes under II and III seismic zonation map of India. Also, one cannot deny the possible vulnerability of this mildly active region. But only a few attempts have been made until today for a hazard-related study of this region. Attenuation characteristics form one of the essential parameters of seismic hazard studies, but few researchers have studied this parameter for EIC to date (Khan et al. 2016). However, the lack of a sufficient number of seismic stations resulting in poor azimuthal coverage and bad quality seismic data constrain those earlier studies. A seismic network of 15 three-component broadband seismographs was deployed by the National Geophysical Research Institute (CSIR-NGRI), Hyderabad, in an area of about $300 \times 500 \mathrm{~km}^{2}$ covering Eastern Indian cratonic regions, to study the crustal evaluation and the cratonic intraplate earthquakes genesis process. During 2013-2014, this network recorded 18 local earthquakes, which enabled us to study the attenuation characteristic of the EIC region through the coda- $Q_{\mathrm{c}}$ estimate of these local earthquakes. A study of coda- $Q_{\mathrm{c}}$ attenuation characteristics of nine well located local earthquakes from the EIC region comprising three geologically and tectonically different areas (the Singhbhum Odisha craton (SOC), the Chotanagpur granitic gneissic terrain (CGGT) and the Eastern Ghat mobile belt (EGMB)) are presented in this paper to understand the attenuation properties of this region.

So far, different models have been used to calculate the attenuation of seismic energy for coda- $Q$ estimations using single or weak scattering models, multiple scattering models, diffusion models and the energy flux model and so on (Aki 1969; Aki and Chouet 1975; Kopnichev 1977; Sato 1977; Gao et al. 1983; Frankel and Wennerberg 1987). Margerin et al. (1998) used Monte-Carlo simulations by considering solutions from analytical results of the diffusion equation to study the multiple scattering models of attenuation. They found that both these methods provide similar exact asymptotic solutions for models with a uniform mean free path, the average distance energy travels before scattering. Assuming intrinsic attenuation with isotropic scattering, Hoshiba (1991) studied the energy conservation law-based coda wave excitation due to multiple scattering. To quantify the contribution of intrinsic and scattering mechanisms to the total attenuation of media, multiple scattering models have also been studied using the radiative transfer method (Wu 1985) and different windows of lapse time studies (Fehler et al. 1992). However, this method became less popular due to its relatively complicated procedures (Chung et al. 2009). Padhy and Subhadra (2010) studied multiple scattering in a three-dimensional model where the energy flux model and the diffusion model were adopted and they found that for a longer lapse time window, more multiple scattering contribution occurs. By considering the uniform distribution of isotropic scatterers in an elastic medium, Gao et al. (1983) examined the influence of multiple scattering on coda waves and they found that the extension of the single scattering theory might explain coda power for shorter lapse times whereas multiple scattering needs to be considered for larger lapse times (>100 s) (Chung et al. 2009). However, the single scattering model is effective for longer lapse times too (Sato 1988).

Sato (1977) proposed the generalised model of Aki and Chouet (1975), wherein the scattering is assumed to be a weak process. Thus, the energy loss of primary waves due to single and multiple scattering is ignored (Born approximation). The single backscattering model has been widely used in different regions in the world for the studies of crustal attenuation characteristics, and the same has been used in the present study. The frequencydependent coda wave quality factor $\left(Q_{\mathrm{c}}\right)$ has been used to investigate the tectonic characteristics of seismically active/mildly active areas around the world (Sato 1977; Rautian and Khalturin 1978; Aki 1980a, b; Herrmann 1980; Roecker et al. 1982; Frankel et al. 1990; Mitchell 1995; Aleqabi and Wysession 2006). In addition, this kind of study of frequency-dependent attenuation characteristics of seismic waves is useful for both seismologists and engineers for predicting ground motions and hazard-related studies (Pulli 1984; Herraiz and Espinosa 1987; Havskov et al. 1989; Sato and Fehler 1998; Paul et al. 2003; Mandal et al. 2004; Allen et al. 2007; Mukhopadhayay and Tyagi 2007; Mukhopadhyay et al. 2008). Seismic wave attenuation characteristics for local or regional earthquake events are calculated by analysing a different kind of seismic waves, i.e., direct waves (Yoshimoto et al. 1993; Hazarika et al. 2013), $L_{g}$ waves, surface waves and coda of S wave or $L_{g}$ waves (Singh and Herrmann 1983). Most of the studies of attenuation properties of the crust are determined using local earthquake data i.e., the coda waves decay time 
is used to measure the attenuation (i.e., $1 / Q$ ) in the Earth's crust (Pulli 1984; Herraiz and Espinosa 1987; Havskov et al. 1989; Sato and Fehler 1998; Mandal et al. 2004; Mukhopadhayay and Tyagi 2007; Mukhopadhyay et al. 2008; Sharma et al. 2008).

In this paper, a time-domain coda-decay method is used to calculate the $Q$ value of local earthquakes (Havskov et al. 1989). The decay rate of the coda wave amplitude with time is used to compute the attenuation properties (Aki 1969; Aki and Chouet 1975; Sato 1977; Aki 1980a; Frankel et al. 1990). Tectonic activity and seismicity are directly related to $Q_{\mathrm{c}}$ value and low $Q_{\mathrm{c}}$ values are associated with active tectonic zones whereas higher $Q_{\mathrm{c}}$ values are associated with stable regions or cratons (Singh and Herrmann 1983; Jin and Aki 1988; Mak et al. 2004; Singh et al. 2004). Recently, Havskov et al. (2016) studied coda $Q$ for different tectonic areas and the interesting thing they found is that coda $Q$ results are very similar to similar tectonics and significantly different for varying tectonics. Here, the frequency-dependent coda- $Q_{\mathrm{c}}$ relation estimate is carried out for three different regions in the Eastern Indian craton, i.e., SOC, CGGT and EGMB, using nine local earthquake data from 15 three-component broadband seismic stations of the Singhbhum regional seismological network of the National Geophysical Research Institute (NGRI), Hyderabad, India. The lapse time dependency of coda $Q$ is also studied for different lapse time windows. The study of the spatial variation of the $Q_{\mathrm{c}}$ relationship is also carried out for exploring the relationship between the tectonic structure and the frequency-dependent $Q_{\mathrm{c}}$ value of the study regions.

\section{Geology of the EIC region}

The part of the Indian peninsular craton under study is surrounded in the south by the EGMB, Ranipather shear zone, Mahanadi fault and the recent coastal alluvium and in the west Gondwana sediment of the Permian to the Palaeoproterozoic age. The vast Gangetic alluvium and sediments of the Quaternary age from the Bengal basin are bounded in the northern and eastern parts of the study area (figure 1). The study area, i.e., EIC can be divided into three tectonic zones: the SOC, which is situated in the centre; the EGMB, which is situated in the south; and the CGGT, which is located in the northern part of the study area (Sarkar 1982). A multi-phase intrusion occurred

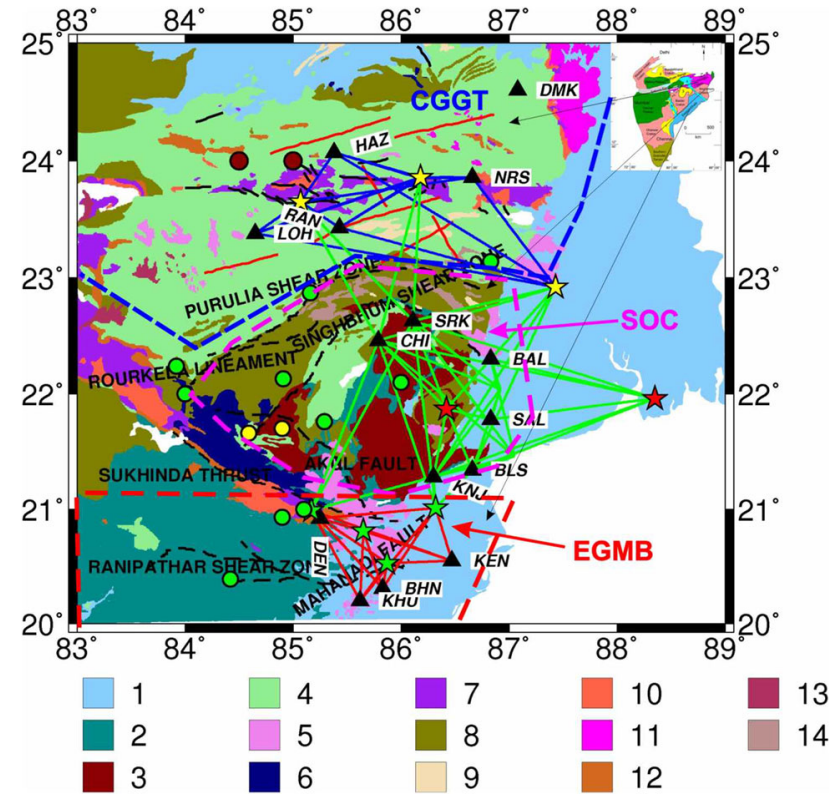

Figure 1. Three study regions have been roughly demarcated by different dotted lines (SOC: pink dotted line; CGGT: blue dotted line and EGMB: red dotted line). Different geological formation of the EIC regions are shown in different colours and number combinations: (1) Quaternary; (2) Archaean; (3) Singhbhum granite; (4) Proterozoic; (5) Cenozoic; (6) Neo-Proterozoic; (7) Permian; (8) Palaeoproterozoic; (9) Mesoproterozoic; (10) Triassic-Jurassic; (11) Jurassic-Cretaceous; (12) Talchir formation; (13) Deccan traps and (14) Dalma volcano. The red lines denote lineaments and black lines denote faults in the CGGT area (the upper part of the map). The dotted black line denotes faults; shear zone and lineament (written in the map) in the SOC and the EGMB areas. The black triangle denotes the stations present in the EIC area (KHU: Khurda, BHN: Bhubaneswar, KEN: Kendrapara, DEN: Denkanal, KNJ: Keonjhor, BLS: Balasore, SAL: Salbani, BAL: Balukuria, CHI: Chaibasa, SRK: Saraikela, LOH: Lohardaga, RAN: Ranchi, HAZ: Hazaribagh, NRS: Nirsa and DMK: Dumka). Earthquakes identified using the single station method are denoted by yellow stars whereas those located using multiple stations are indicated by red stars. Two historical earthquakes are denoted by solid brown circles (viz., 1968 M4.3 Hazaribagh and 1968 M5.7 Manbhum) while two M5 events in 1863 and 1997 are marked by yellow solid circles. Solid green circles denote local earthquakes of M3.0-4.9. Broadband seismograph stations (Black triangle) at the EIC region and the projections of seismic wave paths are shown in blue for the SOC, green for the CGGT and red for the EGMB regions linking the epicentres (shown by solid yellow stars for the SOC, solid red stars for the CGGT and solid green stars for the EGMB regions) and the stations (denoted by solid black triangles) of local earthquakes analysed for the EIC region.

and $3.5 \mathrm{Ga}$ supracrustal successions were found in this area (Mukhopadhyay et al. 2008; Acharyya et al. 2010a, b; Tait et al. 2011; Mazumder et al. 2012 and references therein). The core zone of the Singhbhum area is characterised by the $3.3-3.1 \mathrm{Ga}$ 
Singhbhum granite. Older cratonic rocks of the Archaean and Proterozoic age are found in the SOC and CGGT areas, whereas meta-sediments of the Mesozoic age are found in the EGMB region, and Archaean rocks are also exposed to some part of the area. These regions are very famous for different types of mineral deposition, specially the Singhbhum area, and this region contains gneisses, granites, quartzites and phyllites, semi-metamorphosed shales, etc., and these rocks have experienced several phases of tectonic deformation, metamorphism and metasomatism (Dunn 1929; Sarkar and Chakraborty 1982; Acharya 1984; Ghosh and Sengupta 1990; Chetty and Murthy 1994; Saha 1994). The older metamorphic group that comprises schists is the basement of the area. The older iron ore group rocks overlie the basement rocks and the Dalma volcanic belt overlies the iron ore group and the younger Sighbhum group rocks overlie the Dalma volcanic belt.

\section{Tectonics and seismicity}

As the tectonics and seismicity of any region is directly related to the $Q$ values, it is very important to know the tectonics of the study area. The tectonics and seismicity of the EIC region are described in brief in this section.

\subsection{Tectonics of the EIC region}

Three phases of plate motions between 2.0 and $0.85 \mathrm{Ga}$ are proposed by several researches (Sarkar 1982; Misra 2006) for the EIC region. During the first cycle between 2.0 and $1.6 \mathrm{Ga}$, the northward movement of the Singhbhum plate started and finally collided with the Chotanagpur plate. Due to this collision, metamorphism occurred, folds and thrusts were developed and the Dalmaophiolite belt was tectonically emplaced. During the second phase (1.55-1.17 Ga), the Singhbhum plate rotated clockwise towards the northeast, and due to this movement, a shear zone and folds developed. Finally, during the third phase (1.00$0.85 \mathrm{Ga}$ ), the Singhbhum plate rotated anticlockwise towards the northnorthwest and due to this rotation, the continental lithosphere of this plate obducted and impinged towards the Chotanagpur plate towards the northnorthwest direction. Due to this process, the Singhbhum shear zone developed and during the quiescence period, isostatic readjustments (viz., intrusion of basic dyke swarms, paralic sedimentation, upliftments and erosion) occurred.

\subsection{Seismicity of the EIC region}

Moderate seismicity is observed in the EIC region (Gupta et al. 2014). Historical earthquakes are also reported for this region by several types of research. Two historical earthquakes of M4.3 and 5.7 occurred on July 1868 in Hazaribagh (the CGGT area) and September 1868 in the Manbhum area, respectively (Oldham 1883; Kayal et al. 2009). Singhbhum shear zone also witnessed a noteworthy historical earthquake of M5.2 (8 May 1963) (figure 1). Three moderate sized (ML: 5.3-5.5) earthquakes in Midnapur district of West Bengal were also reported (Chandra 1977). The study of fault plane solutions inferred that maximum compression is N-S oriented in this area and the strikeslip motion is mainly active in the ENE-WSW directed fault plane. From 1986 to 1995, Bonaigarh area near the EGMB and the SOC contact zones also witnessed a total of six moderate earthquakes of magnitude (ML) between 4.1 and 5.0 (Gupta et al. 2014). In 1993, the south of the Sukhinda thrust had experienced one earthquake of ML 4.3 (figure 1). The Geological Survey of India (GSI) also reported 26 smaller earthquakes $(\mathrm{ML}<3.0)$ in the Talchir-Bonaigarh area during 1997. The single station observatory of the Indian School of Mines, Dhanbad, Jharkhand, also reported that around 160 smaller earthquakes occurred near Dhanbad and its nearby regions during 2007-2008 (Khan et al. 2011). A study of moment tensor solutions of these local events also revealed that a left lateral strike-slip motion is prominent in the EIC region (Kayal et al. 2009; Biswas and Mandal 2017). These also indicate that the primary deformation mode in the present study area is a strike-slip sense of motion.

\section{Data and methodology}

\subsection{Data}

In 2013, the CSIR-NGRI, Hyderabad, had deployed a temporary seismic network consisting of 15 broadband seismographs (three components) in the SOC, EGMB and CGGT regions (figure 1). All stations are installed on strong strata to get a higher signal-to-noise ratio. The recording rate of the seismograph was kept at 50 samples per second with high gain. Continuous time series data 
from 2013 to 2014 were analysed from this network. This temporary seismic network recorded numerous regional and teleseismic earthquakes. However, some recorded local earthquakes during the above said period are of very low magnitude for the study area. Only 18 local earthquakes have been identified for this region. These local events are located using SEISAN software (Havskov and Ottemoller 2003). Both single station and multiple station methods have been used to identify these events. Multiple station methods have been used for 10 events and single station method is used for the remaining eight events as these events were recorded in less than three stations. A one-dimensional velocity model of five different sets has been used for the earthquake location which is described in the paper by Biswas and Mandal (2017). One velocity model, the one-dimensional average crustal model, was modified from Kayal et al. (2009). Other four models have been chosen from models generated by the receiver function analysis (Mandal and Biswas 2016).

For our study, events having a magnitude of more than 2.5, signal-to-noise ratio $(\mathrm{S} / \mathrm{N})$ more than 2.0 and a long coda duration were selected to ensure the stable estimates of the coda $Q$. Here, $\mathrm{S}$ is selected to be of $5 \mathrm{~s}$ signal levels of the coda wave which is twice the $\mathrm{S}$ wave travel time, and $\mathrm{B}$ is selected from the pre-event noise $15 \mathrm{~s}$ before the $\mathrm{P}$ wave. Results with less than 0.50 regression correlation coefficients are rejected (Havskov et al. 1989). In this work, nine events out of 18 earthquakes are used for the estimation of attenuation characteristics.

\subsection{Methodology}

Coda wave amplitude $A(f, t)$ for a single back-scattering model (Aki and Chouet 1975) can be written as

$$
A(f, t) \propto \exp \left(-\frac{f t \pi}{Q(f)}\right)
$$

where $f$ is the central frequency and $t$ is the lapse time from the origin $t_{o}$. Now equation (1) can be written as

$$
A(f, t)=K(f) t^{-\alpha} \exp \left(-\frac{f t \pi}{Q(f)}\right)
$$

where $K(f)$ is the time-independent, frequencydependent coda source factor and radiation pattern, and $\alpha$ represents the geometrical spreading parameter which is considered as 1.0 for body waves, 0.5 for surface waves and 0.75 for diffusion scattering, respectively (Havskov et al. 1989). Assuming coda waves are primarily $\mathrm{S}$ to $\mathrm{S}$ backscattered waves (Aki 1981; Kvamme and Havskov 1989), the geometrical spreading parameter $(\alpha)$ is considered to be 1 for this study. By taking the natural logarithm of equation (2), we can write

$$
\begin{gathered}
\ln A(f, t)+\ln (t)=\ln K(f)-\frac{\pi f t}{Q(f)}, \\
\ln [A(f, t) t]=m-b t, \text { for } \alpha=1 .
\end{gathered}
$$

Equation (4) characterises a straight line plot between $\ln (A(f, t) . t)$ and $t$, where slope $b=\pi f / Q(f)$ and $m=\ln K(f)$. The coda- $Q_{\mathrm{c}}$ subroutine in-built in SEISAN 8.0 software (Havskov and Ottemoller $2003)$ is used for the calculation of coda- $Q_{\mathrm{c}}$ values, where lapse time windows are considered from double the S-wave travel time $\left(t_{\text {start }}=2 t_{\mathrm{s}}\right)$. The window is selected so as to reject the contamination effect of the onward scattered waves and direct waves (Rautian and Khalturin 1978). $Q_{\mathrm{c}}$ values increase with lapse time as observed in various parts of the world. This may be because of a deeper depth of penetration of coda waves with increasing lapse time as the attenuation effect is comparatively less with the increasing depth (Roecker et al. 1982; Havskov et al. 1989; Gusev 1995; Giampiccolo et al. 2002). Multiple scattering could also be another reason for increasing $Q_{\mathrm{c}}$ with increasing lapse time (Fehler et al. 1992; Hoshiba 1993). The single-scattering model can explain coda power for a shorter lapse time, but a multiple scattering model is necessary to explain coda power for a longer lapse time (>100 s) (Gao et al. 1983). Thus, different lapse time windows (10-90 s with a step of $10 \mathrm{~s}$ ) starting from $2 t_{\mathrm{s}}$, are selected for the three parts of the study region (SOC, CGGT and EGMB). By poor correlation coefficients, for these three study regions, only six lapse time windows from 40 to $90 \mathrm{~s}$ with a step of $10 \mathrm{~s}$ are taken for the final study. A band-pass filter with central frequencies $\left(f_{m}\right) 2.0$ (1-3 Hz band), 4.0 (2$6 \mathrm{~Hz}$ band), 8.0 (6-10 Hz band), 12.0 (10-14 Hz band), 16.0 (12-20 Hz band) and $18.0(12-24 \mathrm{~Hz}$ band) $\mathrm{Hz}$ has been used for all selected seismograms. An increasing frequency band to increase 


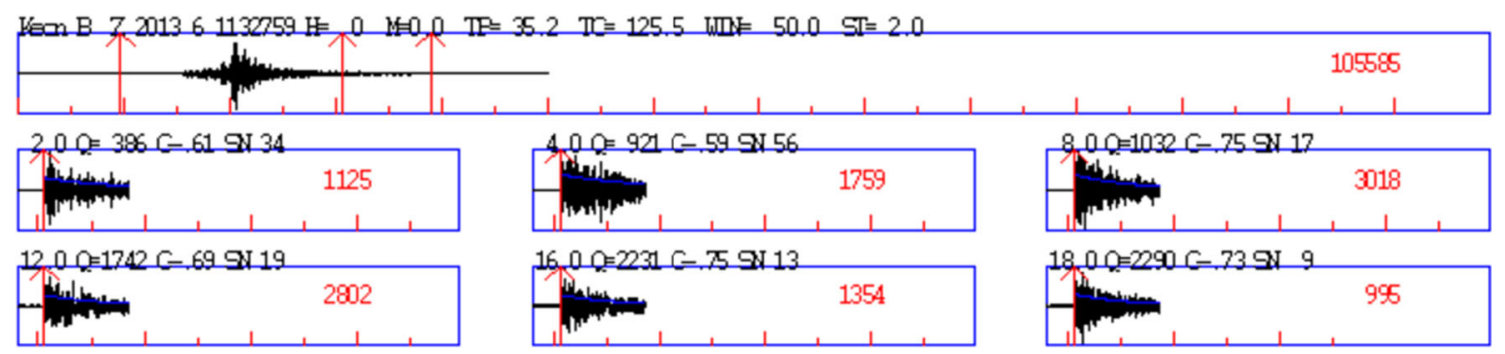

Figure 2. Filtered seismograms recorded at Keonjhor (KNJ) station. The top part of the figure shows the vertical component seismogram from station KNJ in which the first red arrow on the left side indicates origin time, and the other two red arrows on the right side show the coda duration. Filtered coda windows for six central frequencies at $t_{\text {start }}=2 t_{\mathrm{s}}$ are shown in each set of boxes in the lower part of the figure. The number on the left-hand side within each box represents the central frequency in Hertz. Tick marks on the $x$-axes for all boxes are at an interval of $30 \mathrm{~s}$. The $y$-axis represents amplitude. Abbreviations: $\mathrm{Q}: Q_{\mathrm{c}}$ and $\mathrm{SN}$ : signal-to-noise ratio.

the central frequency has been considered to diminish the ringing effects and to get the same energy distribution for each band (Havskov and Ottemoller 2003). A root-mean-square (RMS) method has been applied for smoothing each filtered coda part. In this method, a sliding window length of $5 \mathrm{~s}$ along the coda in steps of $2.5 \mathrm{~s}$ has been used, and the value at each step in the same frequency band has been evaluated. The vertical component of waveform data of the Keonjhor (KNJ) station has been shown in figure 2 and filtered waveform data at different frequencies are also shown in the figure.

The coda- $Q_{\mathrm{c}}$ values are estimated for all 18 local events, but due to different noise factors for different stations, all the event/station combinations could not be considered for the coda- $Q_{\mathrm{c}}$ estimation and only nine events could be used for this study. A positive correlation between frequency and $Q_{\mathrm{c}}$ has been observed in many regions around the world, where coda- $Q_{\mathrm{c}}$ estimations have been carried out. The positive correlation between $Q_{\mathrm{c}}$ and frequency can be expressed in the following form:

$$
Q_{\mathrm{c}}(f)=Q_{0} f^{n}
$$

$Q_{0}$ is the magnitude of $Q_{\mathrm{c}}$ at frequency $1 \mathrm{~Hz}$ (Pulli 1984; Herraiz and Espinosa 1987; Havskov et al. 1989).

Seismic energy decay can be explained in terms of geometrical spreading, scattering attenuation for heterogeneous medium and intrinsic attenuation due to inelastic processes in rocks (Aki and Chouet 1975). The shape and the frequency content of the earthquake seismogram can be determined from a combination of source, site effects and attenuation propagation effects. To determine one of these effects, the other two effects have to be removed. Thus, it is essential to understand the attenuation characteristics while calculating seismic source parameters and hazards. Now the seismic wave attenuation can be considered as the summation of scattering and intrinsic attenuation (Zeng et al. 1991). For intrinsic attenuation, the energy loss is due to the shear heating at grain boundaries, mineral dislocations while the energy loss for scattering attenuation is because of refraction, reflection and conversion caused by inhomogeneous rock properties and the existence of cracks and fractures (Mitchell 1981; Padhy 2009). In other words, the scale of heterogeneity in space describes the scattering attenuation, while the scale in time (relaxation time) illustrates the intrinsic absorption (Padhy 2009).

Now, the energy attenuation from primary waves and multiple scattering is not considered in a single backscattering model. Thus, coda- $Q_{\mathrm{c}}$ amplitude loss is primarily because of intrinsic attenuation. According to the single backscattering theory, the energy from the primary field is lost with distance due to scattering unless it reaches the seismic instruments (Aki 1980a). So, coda $Q_{\mathrm{c}}$ is an effective $Q$, and it is a combination of both scattering attenuation $\left(Q_{\mathrm{s}}\right)$ and intrinsic attenuation $\left(Q_{\mathrm{i}}\right)$. The relation between $Q_{\mathrm{c}}$, intrinsic and scattering attenuation can be represented by the following equation (Dainty and Toksoz 1981):

$$
\frac{1}{Q_{\mathrm{c}}(f)}=\frac{1}{Q_{\mathrm{i}}}+\frac{1}{Q_{\mathrm{s}}} .
$$

As the primary contribution to the singlescattering theory comes from intrinsic attenuation, considering $Q_{\mathrm{i}}=\infty$, equation (6) can be written as 

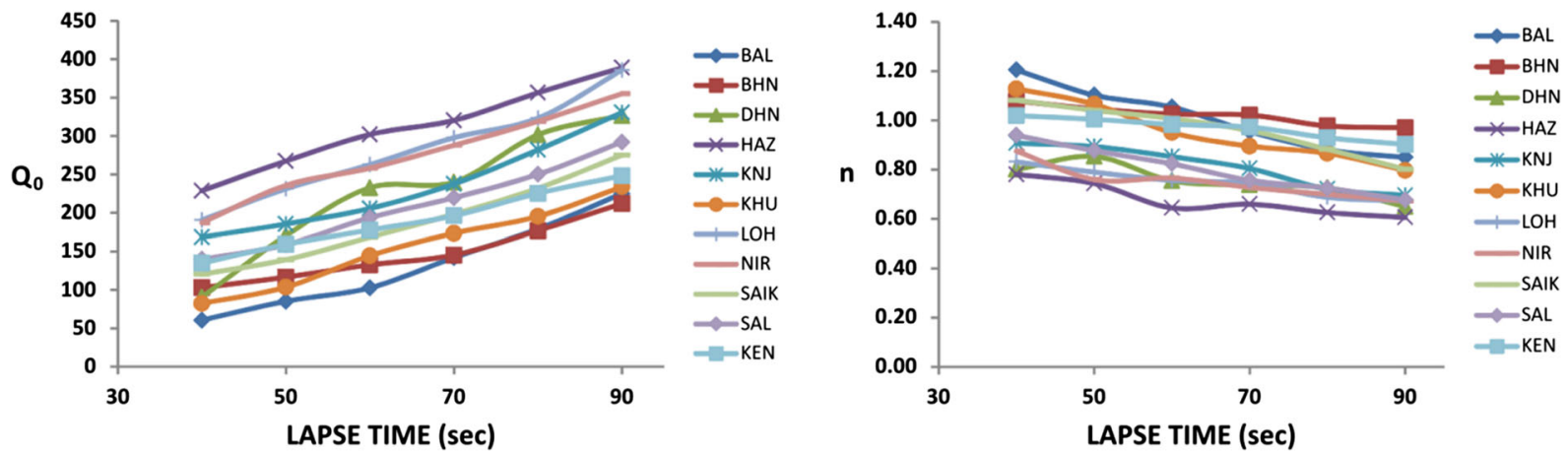

Figure 3. Plot showing lapse time vs. $Q_{0}$ and lapse time vs. exponent $(n)$ value.
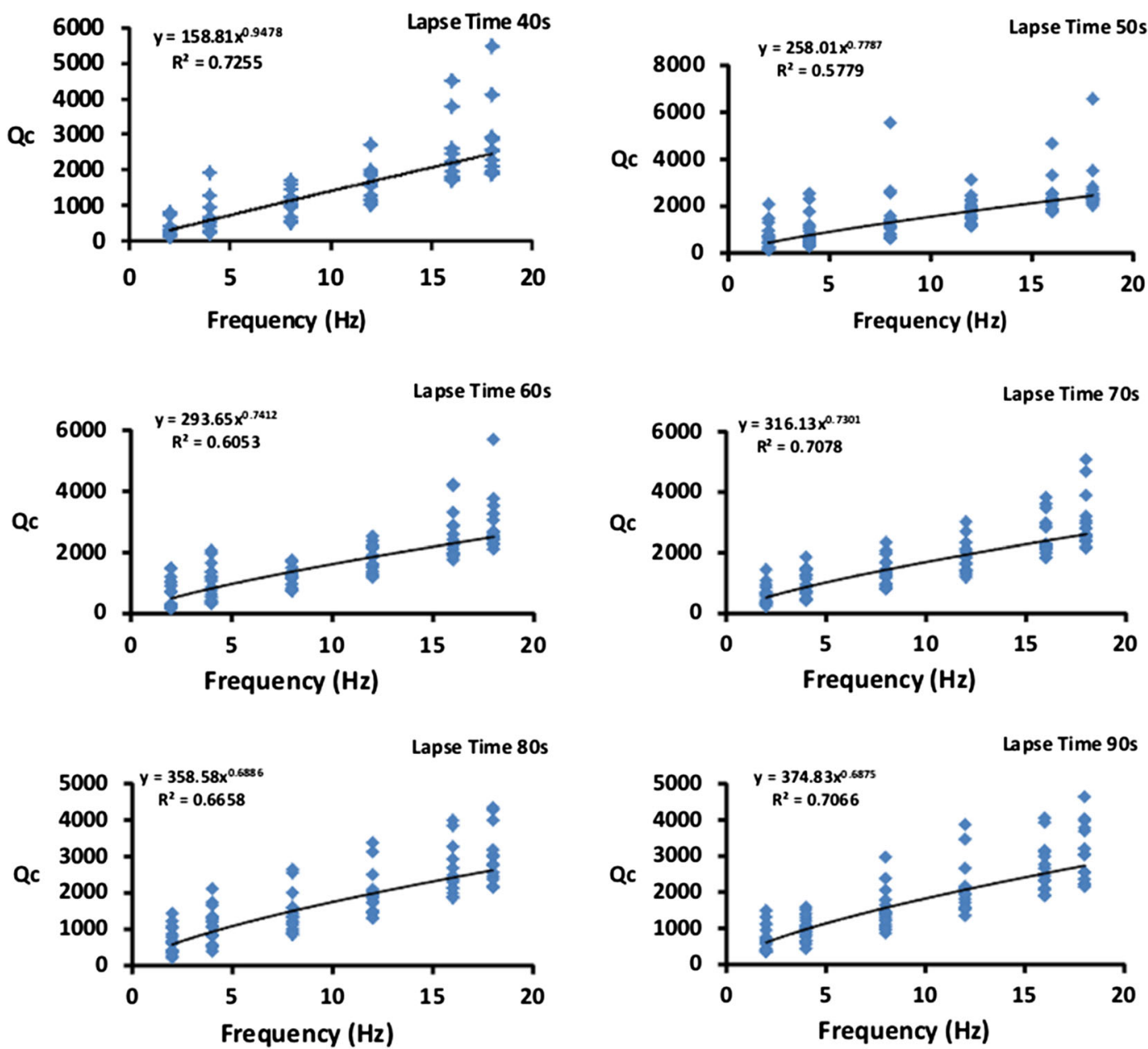

Figure 4. Plot showing frequency vs. $Q_{\mathrm{c}}$ at different lapse times for the SOC region.

follows:

$$
\frac{1}{Q_{\mathrm{c}}(f)}=\frac{v}{2 \pi L_{\mathrm{e}}}
$$

Here, $L_{\mathrm{e}}$ is the extinction distance and $v$ is the shear wave velocity. The extinction distance $\left(L_{\mathrm{e}}\right)$ provides knowledge about the scatterer distribution in the lithosphere. Primary energy to the scattered energy transmission throughout the travelled path is also controlled by $L_{\mathrm{e}}$. The mean energy flux density of the incident plane wave reduces to $\exp \left(-x / L_{\mathrm{e}}\right)$, through scatterers, where $x$ is the distance along the propagation direction. The extinction distance is computed from the mean values of $Q_{c}$. Shear wave velocity is considered $3.8 \mathrm{~km} / \mathrm{s}$ for the SOC and CGGT regions and 
$3.5 \mathrm{~km} / \mathrm{s}$ for the EGMB region (Mandal and Biswas 2016). Anelastic attenuation $(\gamma)$ caused by fluid movement and grain boundary friction is also calculated using the following equation (Nuttli 1973):

$$
\gamma=\left[\frac{\pi f}{Q_{\mathrm{c}}(f)}\right] U
$$

Here, $U$ is the group velocity which is equivalent to shear wave velocity $(3.8 \mathrm{~km} / \mathrm{s}$ for the $\mathrm{SOC}$ and CGGT regions and $3.5 \mathrm{~km} / \mathrm{s}$ for the EGMB region) and $f$ is the frequency.

As the seismic network comprising the EGMB, CGGT and SOC regions, the attenuation estimates are divided into three regions (figure 1) (SOC (demarcated by a pink dotted line), CGGT (demarcated by a blue dotted line) and EGMB (demarcated by a red dotted line)) by geological and tectonic settings and attenuation characteristics. Seismic wave paths between stations and earthquake epicentres for the three study regions are shown in figure 1.
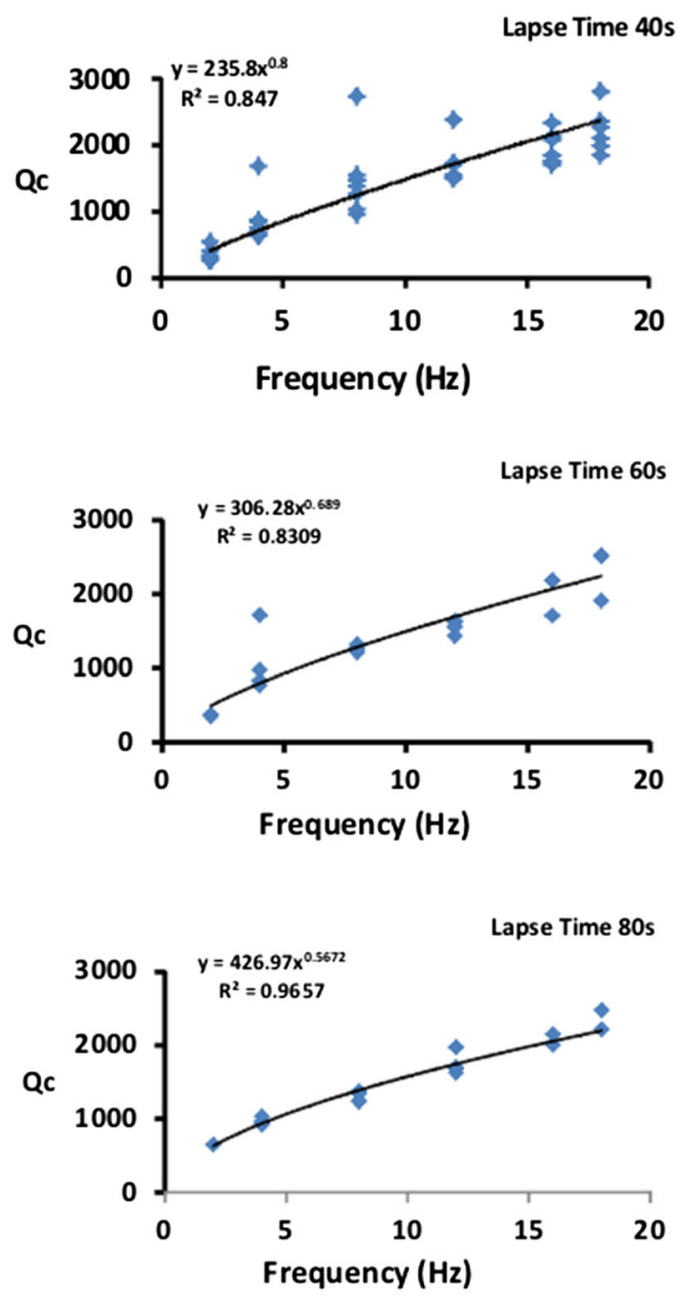

\section{Results and discussion}

The $Q_{\mathrm{c}}$ value has been computed at six central frequencies 2, 4, 8, 12, 16 and $18 \mathrm{~Hz}$ using the digital broadband data of the EIC. Though the study regions consist of 15 broadband seismometers, we could use data from 11 stations for coda $Q$ estimations. Data from four stations were rejected on the ground of poor $\mathrm{S} / \mathrm{N}$ level and meagre correlation coefficients. Stations KNJ, BLS, SAL and SRK fall in the SOC region; stations $\mathrm{LOH}, \mathrm{HAZ}$ and NRS fall in the CGGT region and stations KHU, KEN, BHN and DEN are part of the EGMB region. The estimated coda $Q$ and exponent $n$ (for different lapse time $[40-90 \mathrm{~s}]$ ) values for various stations are shown in figure 3 . A clear increase in $Q_{\mathrm{c}}$ values with frequency can be seen for any lapse time for all broadband stations, and this shows a strong frequency dependency of coda $Q$ values (figure 3). The estimated $Q_{\mathrm{c}}$ values are relatively lower for the same frequency and the same lapse
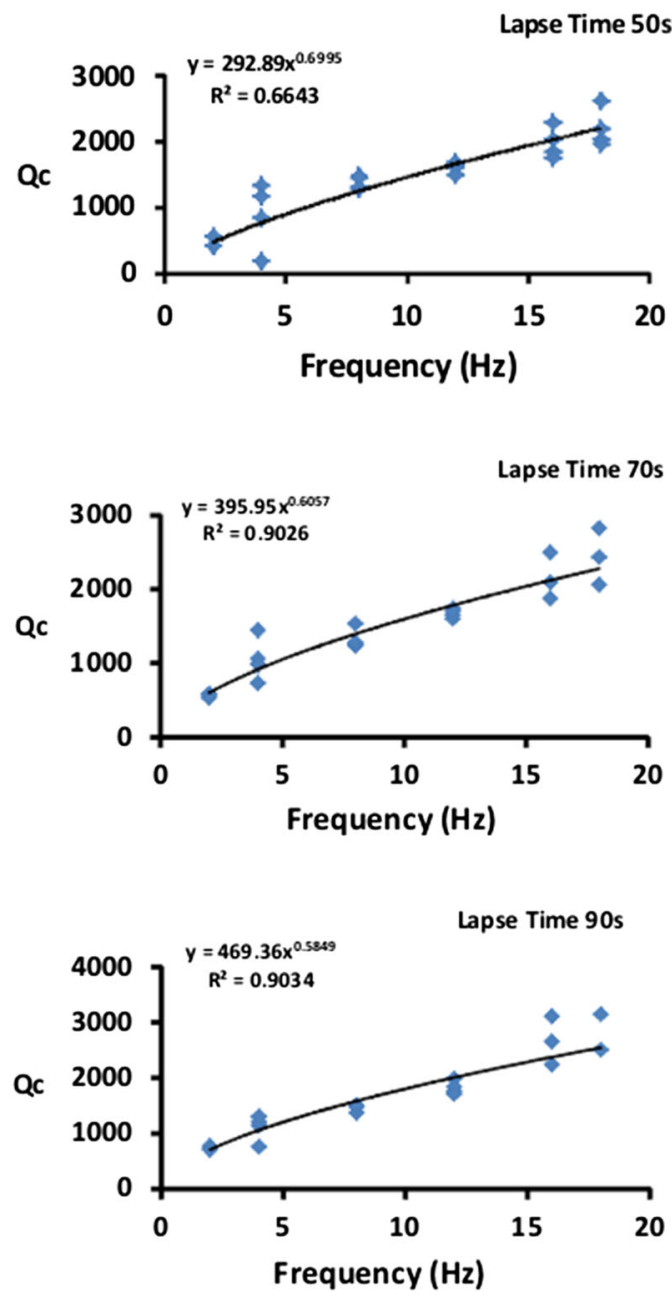

Figure 5. Plot showing frequency vs. $Q_{\mathrm{c}}$ at different lapse times for the CGGT region. 

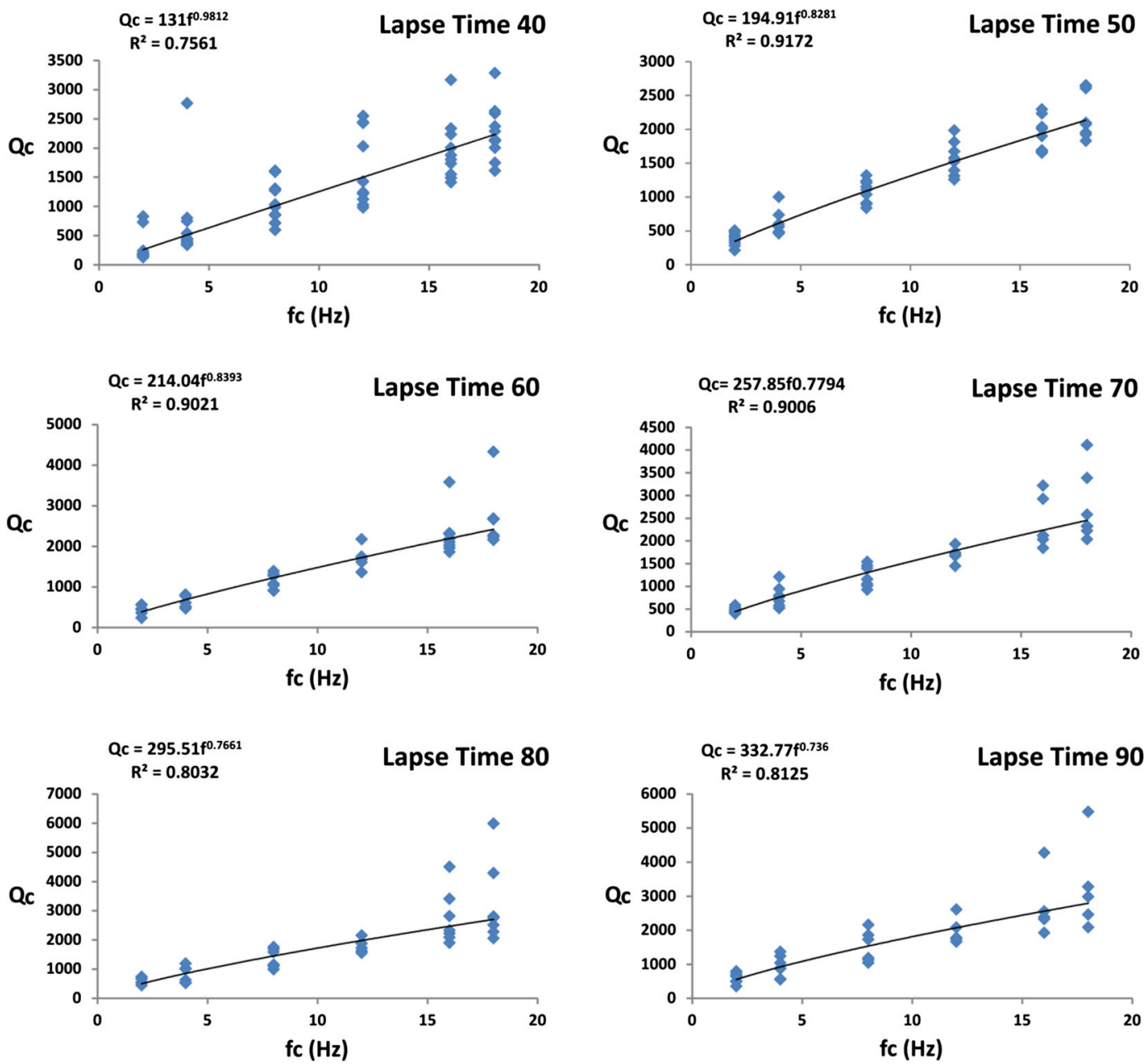

Figure 6. Plot showing frequency vs. $Q_{\mathrm{c}}$ at different lapse times for the EGMB region.

time for stations BLS, BHN, DHN, KHU and KEN, which in the EGMB (except BLS) sediments and near the coastline (figure 1). Station BLS is situated near the Singhbhum Shear zone, which may be the reason for the lower $Q_{\mathrm{c}}$ value as shear zones are highly heterogeneous and complex in nature. The remaining stations HAZ, KNJ, LOH, NIR and SAL have relatively high $Q_{\mathrm{c}}$ value as those stations are situated on the hard formation of the Singhbhum Odisha craton (SOC) and the CGGT region, which are relatively more stable and homogeneous. It is found that $Q_{\mathrm{c}}$ values in the stations of CGGT (LOH, NIR and HAZ) are a little bit high in comparison with that in the SOC region. This can be attributed to the fact that the Singhbhum Odisha craton (SOC) comprises the shear zone, which is highly heterogeneous, consisting different minerals, ore bodies and fault scarps, thus seismic waves are more attenuated in comparison with the CGGT region. The plots of frequency vs. $Q_{\mathrm{c}}$ measurements are shown in figures 4-6, which suggest that there is a certain frequency dependency of $Q_{\mathrm{c}}$ in the EIC area. The average $Q_{\mathrm{c}}$ values with a frequency-dependent relation (frequency range $2-18 \mathrm{~Hz}$ ) for the three regions are computed to be $(159 \pm 1) f^{(0.95 \pm 0.01)},(258 \pm 1) f^{(0.78 \pm 0.01)}$, $(294 \pm 1) f^{(0.74 \pm 0.01)},(316 \pm 1) f^{(0.73 \pm 0.01)},(359$ $\pm 1) f^{(0.69 \pm 0.01)},(375 \pm 1) f^{(0.69 \pm 0.01)}$ for the SOC region; $(236 \pm 1) f^{(0.80 \pm 0.01)},(293 \pm 1) f^{(0.70 \pm 0.01)}$, $(306 \pm 1) f^{(0.69 \pm 0.01)},(396 \pm 1) f^{(0.61 \pm 0.01)},(427 \pm$ 1) $f^{(0.57 \pm 0.01)},(469 \pm 1) f^{(0.58 \pm 0.01)}$ for the CGGT region and $(131 \pm 1) f^{(0.98 \pm 0.01)},(195 \pm 1) f^{(0.83 \pm 0.01)}$, $(214 \pm 1) f^{(0.84 \pm 0.01)},(258 \pm 1) f^{(0.78 \pm 0.01)},(296$ $\pm 1) f^{(0.77 \pm 0.01)}$ and $(333 \pm 1) f^{(0.74 \pm 0.01)}$ for the EGMB region, for lapse time windows of 40, 50, 60, 70, 80 and $90 \mathrm{~s}$, respectively. For the EGMB region, the estimated $Q_{\mathrm{c}}$ values are comparatively less than those of the SOC and CGGT regions. This observation suggests that the crustal structure is relatively more heterogeneous and attenuative 
in comparison with that of the SOC and CGGT regions. For the SOC region, we estimate $Q_{0}=$ 159-294 and $n=0.74-0.95$ for $t_{\mathrm{L}}=40-60 \mathrm{~s}$, while we find $Q_{0}=316-375$ and $n=0.69-0.73$ for $t_{\mathrm{L}}=70-90 \mathrm{~s}$. For the CGGT region, we estimate $Q_{0}=236-306$ and $n=0.69-0.80$ for $t_{\mathrm{L}}=40-60 \mathrm{~s}$ while we find $Q_{0}=396-469$ and $n=0.58-0.61$ for $t_{\mathrm{L}}=70-90 \mathrm{~s}$. For the EGMB region, we estimate $Q_{0}=131-214$ and $n=0.84-0.98$ for $t_{\mathrm{L}}=40-60$ s while we find $Q_{0}=258-333$ and $n=0.74-0.78$ for $t_{\mathrm{L}}=70-90 \mathrm{~s}$. Thus, the above-discussed results suggest more heterogeneity for the EGMB region than that for the SOC and CGGT regions. These estimates of $Q_{0}$ and $n$ in the above three regions of EIC are fairly correlatable with the estimation of $Q_{0}$ and $n$ for the mildly active (less heterogeneous) seismic zones in the world.

The estimated exponent $n$ articulates an overall decrease with $t_{\mathrm{L}}$ (figures 4-6) for all three study regions, and prominent mirror symmetry of exponent $n$ with $Q_{0}$ values is observed for all three study regions. These kinds of mirror symmetric correlations between $Q_{0}$ and $n$ against lapse time were earlier testified for different areas in the world. Some of these reported areas are as the Parecis basin, Amazon craton (Brazil), Pannonian basin (Croatia), Almeria basin (Spain), Andaman (India), northwestern Himalaya (India) and Kachchh (Pujades et al. 1997; Mukhopadhyay et al. 2006; Parvez et al. 2008; Barros et al. 2011; Dasovic et al. 2013; Biswas et al. 2016 and references therein). For all the regions around the world, the study result for exponent $n$ suggests that the value of $n$ decreases with increasing lapse time and the same results are found in the present study area. This may be the reason due to the scattered wave which comes from a greater depth to the station. Hence, frequency dependency of the $Q$ factor at a relatively deeper depth would be less than that for the shallower depth/vicinity of the earth surface. This happens when attenuation reaches towards one of the Newtonian solids for which $n=0$ (Dasovic et al. 2013). This is also fit for the lapse time-dependent $n$ value, i.e., increasing the lapse time decreases the $n$ value.

Also, increasing the degree of homogeneity with depth could be another explanation for this as the density of the big scatter increases with depth. This produces low-frequency energy for scatterers and longer coda amplitudes for which apparent attenuation becomes less (Dasovic et al. 2013). Results from an analytical modelling study by Gusev
(1995) also support these observations. There are drawbacks for our modelling of coda $Q$ study as dependent velocities, and multiple scattering is not considered in our model and could also affect the quality factor for lapse-time dependency (Herak 1991; Sato and Fehler 1998).

We also estimate anelastic attenuation coefficients and extinction distances by considering an entirely intrinsic attenuation. The extinction distances (corresponding anelastic attenuation coefficients) are found to be $86.86 \mathrm{~km}\left(0.0058 \mathrm{~km}^{-1}\right)$, $100.91 \mathrm{~km}\left(0.0051 \mathrm{~km}^{-1}\right), 106.59 \mathrm{~km}\left(0.0049 \mathrm{~km}^{-1}\right)$, $112.44 \mathrm{~km}\left(0.0047 \mathrm{~km}^{-1}\right), 117.08 \mathrm{~km}\left(0.0045 \mathrm{~km}^{-1}\right)$ and $121.34 \mathrm{~km}\left(0.0043 \mathrm{~km}^{-1}\right)$ for the SOC region; $95.91 \mathrm{~km}\left(0.0053 \mathrm{~km}^{-1}\right), 98.58 \mathrm{~km}\left(0.0054 \mathrm{~km}^{-1}\right)$, $101.06 \mathrm{~km} \quad\left(0.0052 \mathrm{~km}^{-1}\right), \quad 113.06 \mathrm{~km} \quad(0.0049$ $\left.\mathrm{km}^{-1}\right), 113.53 \mathrm{~km}\left(0.0049 \mathrm{~km}^{-1}\right)$ and $126.93 \mathrm{~km}$ $\left(0.0044 \mathrm{~km}^{-1}\right)$ for the CGGT region and $70.48 \mathrm{~km}$
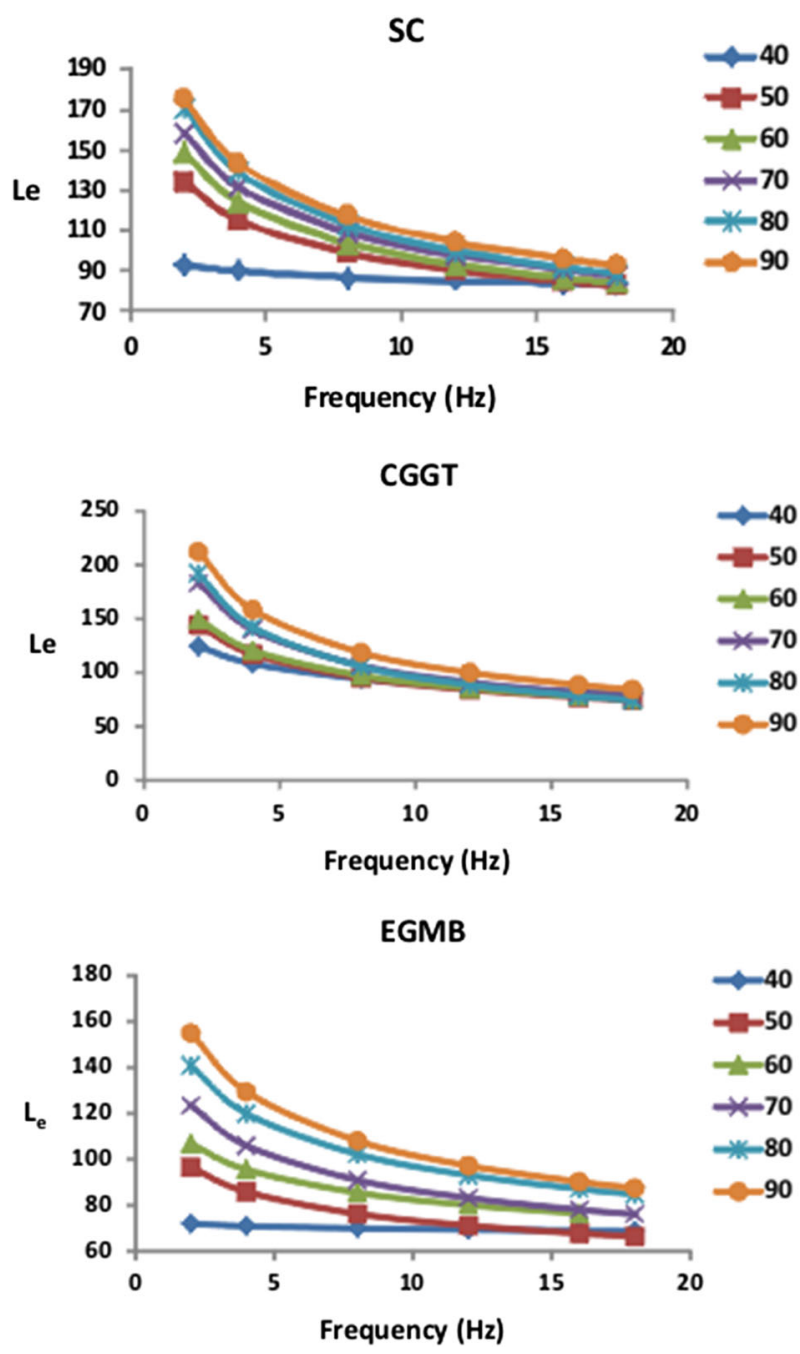

Figure 7. Plot showing frequency vs. extinction distance for the three study regions. 
$\left(0.0071 \mathrm{~km}^{-1}\right), 77.35 \mathrm{~km}\left(0.0066 \mathrm{~km}^{-1}\right), 86.55 \mathrm{~km}$ $\left(0.0059 \mathrm{~km}^{-1}\right), 92.94 \mathrm{~km}\left(0.0055 \mathrm{~km}^{-1}\right), 104.62 \mathrm{~km}$ $\left(0.0049 \mathrm{~km}^{-1}\right)$ and $111.20 \mathrm{~km}\left(0.0047 \mathrm{~km}^{-1}\right)$ for the EGMB region, respectively, for 40, 50, 60, 70, 80 and $90 \mathrm{~s}$ lapse time windows (figure 7). For all three study regions increasing extinction length with increasing lapse time and decreasing attenuation coefficient with increasing lapse time are observed. It is also noticed that there are very less variations in extinction length and attenuation coefficient or more or less constant after a certain lapse time window. This critical window for the EGMB, SOC and CGGT regions is considered to be 70,80 and $70 \mathrm{~s}$, respectively.

These observations conclude that after a $70 \mathrm{~s}$ lapse time for the EGMB area, no significant attenuation exists and this area turns homogeneous (relatively) with increasing depth and it is similar for the SOC and CGGT regions after the 80 and $70 \mathrm{~s}$ lapse time, respectively. It is evident from figure 7 that a stable extinction distance is observed for a relatively higher frequency for all three study areas $(12 \mathrm{~Hz}$ for EGMB; $15 \mathrm{~Hz}$ for SOC and 12 $\mathrm{Hz}$ for CGGT). An idea of scatter distribution in the lithosphere can be known from the extinction distances which also regulate the energy transmission from the primary wave to the scattered waves during the entire travelled pathway. For the SOC region, $L_{\mathrm{e}}$ varies from 86 to $121 \mathrm{~km}$; for the CGGT region, $L_{\mathrm{e}}$ varies from 95 to $126 \mathrm{~km}$ and for the EGMB region, $L_{\mathrm{e}}$ varies from 70 to $111 \mathrm{~km}$. This observation advocates that for all three regions, the upper mantle is relatively less heterogeneous and attenuation below $110-126 \mathrm{~km}$ depth is also less.
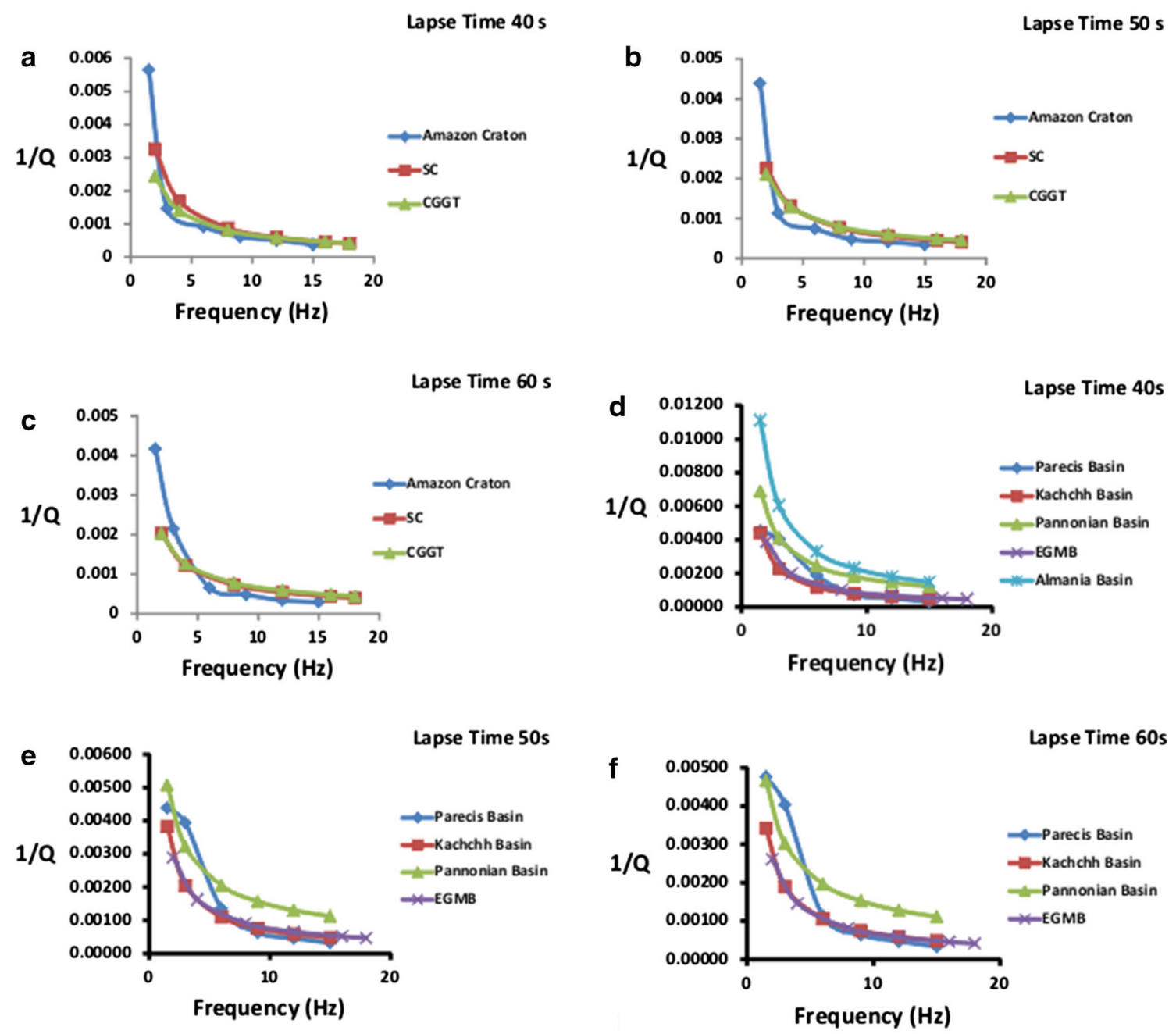

Figure 8. Comparison of estimated $Q_{\mathrm{c}}$ of the SOC and the CGGT regions with the computed $Q_{\mathrm{c}}$ from the Amazon craton $(\mathbf{a}-\mathbf{c})$; and a comparison of the $Q_{\mathrm{c}}$ estimate of the EGMB region with the $Q_{\mathrm{c}}$ estimates from different basins in the world are shown $(\mathbf{d}-\mathbf{f})$. 


\section{Lapse Time $40 \mathrm{~S}$}

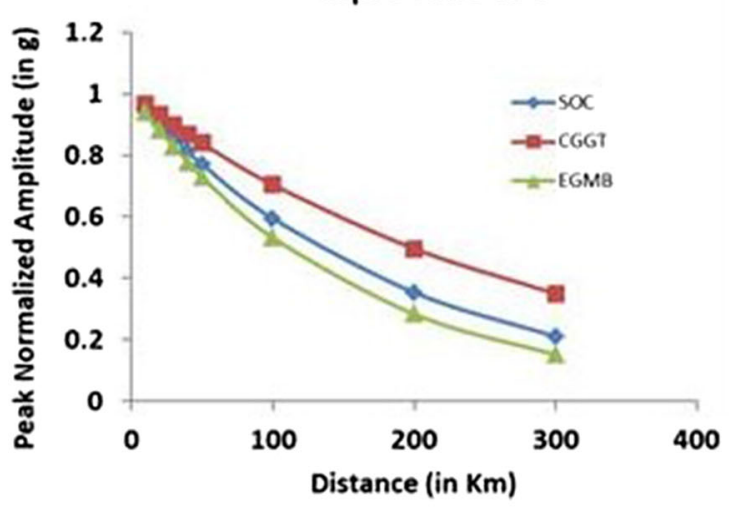

Lapse time 60

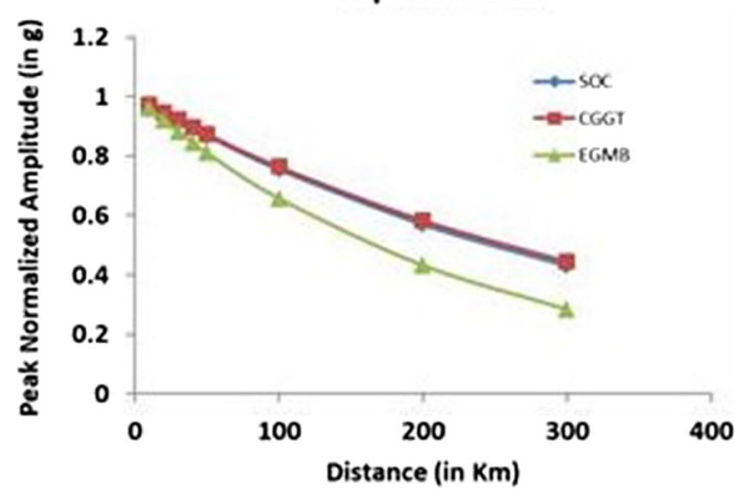

Lapse Time $80 \mathrm{~S}$

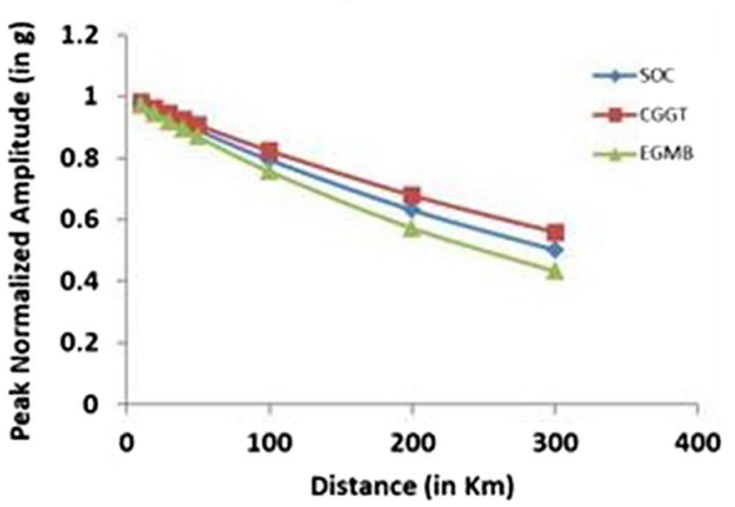

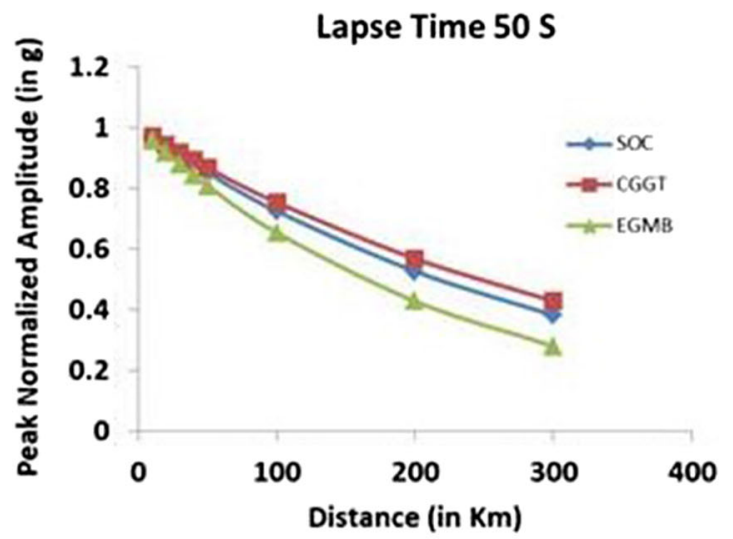

Lapse Time $70 \mathrm{~S}$

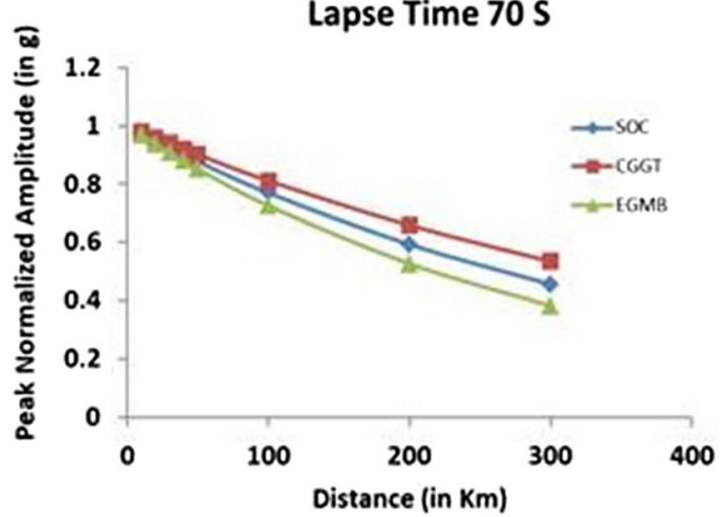

Lapse Time $90 \mathrm{~S}$

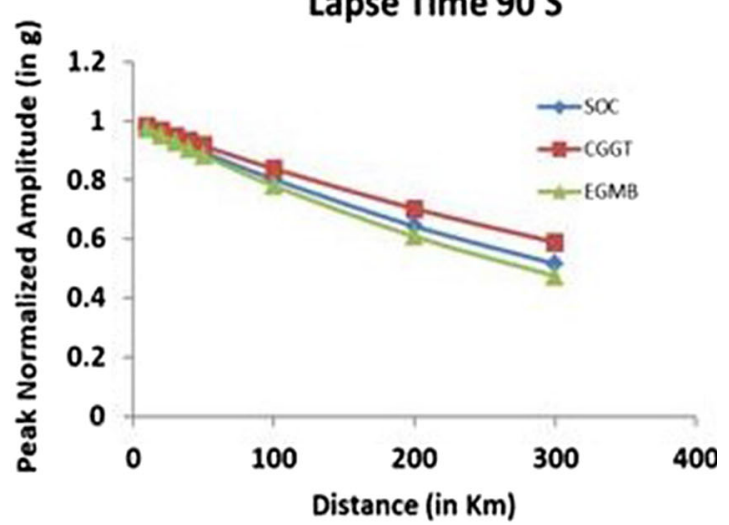

Figure 9. A plot of variation of computed normalised amplitude with distance for three different regions (SOC, CGGT and EGMB) for different lapse times.

\section{Comparison of estimated $Q_{\mathrm{c}}$ values with other areas}

Here, a comparison study (figure 8) of the calculated $Q_{\mathrm{c}}$ values of the SOC, CGGT and EGMB regions with that of other areas of the world including the Amazon craton, Parecis basin (Brazil), Pannonian basin (Croatia), and the Almeria basin (Spain) (Pujades et al. 1997; Barros et al. 2011; Dasovic et al. 2013) was carried out. As the SOC and CGGT regions comprise the older metamorphic, gneissic and other older geological rocks and relatively more stable and homogeneous ones, we have compared the lapse time-dependent $Q_{\mathrm{c}}$ estimate for those two regions with the Amazon craton (figure $8 \mathrm{a}-\mathrm{c}$ ). For most of the EGMB region, sampling the crustal volume by coda $Q_{\mathrm{c}}$ and path covering the available stations fall within the Mahanadi shear zone and the sediment-covered areas, so we have compared the lapse time-dependent coda $Q_{\mathrm{c}}$ estimate for the EGMB region with other basins as the Pannonian 
basin (Croatia), Almeria basin (Spain) and Parecis basin (Brazil) (figure 8d-f). Since the $Q_{\mathrm{c}}$ estimates for the above areas are available only for the 40 , 50 and 60 s lapse time windows, only those particular lapse time windows were compared with our $Q_{\text {c }}$ estimates from the EIC region. We observed that the computed $Q_{\mathrm{c}}$ values for the SOC and CGGT regions are a bit higher than the $Q_{\mathrm{c}}$ value of the Amazon craton. This may be because the crustal structure and properties associated with the SOC and CGGT regions are comparatively homogeneous than those associated with the Amazon craton. Also, the estimated coda $Q_{\mathrm{c}}$ value for the EGMB region is found to be moderate compared to that of other basins in the world which also support moderate seismicity in this area.

\section{Ground acceleration variation with distance}

For the seismic hazard estimation, ground motion prediction is the key factor which helps design safe structures. Ground motion prediction depends on the attenuation of the medium. This attenuation variation with distance can be obtained by the following relation:

$$
A=A_{0} \exp ^{-\alpha x}
$$

where $\alpha=\pi f / Q \beta$ and $x$ is the distance in kilometres. Here $f$ is the frequency and $\beta$ is the S-wave velocity which has been used as $3.8 \mathrm{~km} / \mathrm{s}$ for the SOC and CGGT regions and $3.5 \mathrm{~km} / \mathrm{s}$ for the EGMB region. Ground acceleration variation with distance has been computed for three study regions for different $Q$ values (at $1 \mathrm{~Hz}$ ) at different lapse times (40-90 s) considering distances from 10 to $300 \mathrm{~km}$ (figure 9). From figure 9, it is evident that for a lapse time of $50 \mathrm{~s}$ and at a distance of $300 \mathrm{~km}$, peak normalised amplitudes $\left(A / A_{0}\right)$ reduce to 38 , 43 and $28 \%$ for the SOC, CGGT and EGMB regions, respectively. So ground motion variation for the EGMB region is low compared to the SOC and CGGT regions. So even if a large intraplate earthquake (such as the $2001 M_{\mathrm{w}} 7.7$ Bhuj event) occurs in these regions and ground acceleration generated by the earthquake at the source becomes $1 g$, then the earthquake can cause significant damages up to epicentral distances beyond $300 \mathrm{~km}$ in the SOC and CGGT regions. However, the probability of occurrence of large earthquakes in these regions is very low.

\section{Conclusions}

A single backscattering model is used for studying coda attenuation from broadband waveform data of nine local earthquakes from 15 broadband seismograph stations in the EIC region. This study reveals information regarding attenuation characteristics $\left(Q_{0}, n\right.$ and $\left.L_{\mathrm{e}}\right)$ of three tectonically and geologically different regions (SOC, CGGT and EGMB). The higher $\mathrm{S} / \mathrm{N}$ level (with $\mathrm{S} / \mathrm{N}$ $>2.0$ ) bearing digital local earthquake waveform data from the three-component broadband seismographs empower us to attain robust computations of coda- $Q_{\mathrm{c}}$ attenuation characteristics for the three study regions. A strong frequency dependency of coda $Q_{\mathrm{c}}$ is observed for all three studied regions and it follows the conventional formula. Also, the lapse-time dependency of coda $Q_{\mathrm{c}}$ is noticed from the study. The estimated $Q_{0}$ and $n$ for the three study regions of EIC are well correlatable with the estimation of $Q_{0}$ and $n$ for the mildly active (less heterogeneous) seismic zones in the world. The estimated $Q_{0}$ values in the CGGT region are found to be a little higher in comparison to that of the Precambrian SOC region and the sedimentary-rich EGMB region. This can be attributed to the fact that a seismically less active relatively homogenous granitic terrain, in general, comprises high $Q_{0}$ values than the shear zone comprising the Singhbhum Odisha craton and the sedimentaryrich EGMB is more attenuative, characterised by low coda $Q_{0}$ values. Extinction distance and attenuation coefficient results also suggest that for all three regions, the upper mantle is relatively less heterogeneous and attenuation below 110-126 km depth is also less. The developed $Q_{\mathrm{c}}$ relations might be suitable for computing ground motion associated with the SOC, CGGT and EGMB regions, thereby, assessing the seismic hazard. Our study also validates the result of coda $Q_{\mathrm{c}}$ studies for different tectonic settings, i.e., varying tectonic results for different coda $Q_{\mathrm{c}}$ values. The study of the decay of amplitude with distance suggests that the SOC and the CGGT regions are comparatively more homogeneous than the EGMB region and a large earthquake can cause significant damages to the SOC and CGGT regions beyond $300 \mathrm{~km}$ of distance. Note that only nine of properly located events were used for this study. Thus, a detailed coda- $Q$ attenuation study using a large number of events is required to make any major inferences related to the seismic hazard of the region. 


\section{Acknowledgements}

The authors are grateful to the director, NGRI, Hyderabad, for his kind permission to publish this work. This study was supported by the Council of Scientific and Industrial Research (CSIR) twelfth five-year plan project (INDEX) at the CSIR-National Geophysical Research Institute, Hyderabad.

\section{References}

Acharya S 1984 Stratigraphic and structural evolution of the rocks of the iron ore basins in Singhbhum-Orissa Iron Ore Province, India; CEISM Semin., Ind. J. Earth Sci. 1 19-28.

Acharyya S K, Gupta A and Orihashi Y 2010a New U-Pb zircon ages from Palaeo-Mesoarchaean TTG gneisses of the Singhbhum Craton, eastern India; Geochem. J. 44 81-88.

Acharyya S K, Gupta A and Orihashi Y 2010b NeoarchaeanPalaeoproterozoic stratigraphy of the Dhanjori basin, Singhbhum craton, Eastern India: And recording of a few $\mathrm{U}-\mathrm{Pb}$ zircon dates from its basal part; J. Asian Earth Sci. 39 527-536.

Aki K 1969 Analysis of the seismic coda of local earthquakes as scattered waves; J. Geophys. 74 615-631.

Aki K 1980a Attenuation of shear waves in the lithosphere for frequencies from 0.05 to $25 \mathrm{~Hz}$; Phys. Earth Planet. Inter. 21 50-60.

Aki K 1980b Scattering and attenuation of shear waves in the lithosphere; J. Geophys. Res. 85 6496-6504.

Aki K 1981 Attenuation of short-period seismic waves in lithosphere; In: Proceedings of the Nato Advanced Institute, August 1980, Oslo, Norway.

Aki K and Chouet B 1975 Origin of Coda waves: Source, attenuation and scattering effects; J. Geophys. Res. 80 3322-3342.

Aleqabi G I and Wysession M E 2006 Q Lg distribution in the Basin and Range Province of the western United States; Bull. Seismol. Soc. Am. 96 348-354.

Allen T I, Cummins P R, Dhu T and Schneider J F 2007 Attenuation of ground-motion spectral amplitudes in southeastern Australia; Bull. Seismol. Soc. Am. 971279 1292 .

Barros L V, Assumpco M, Quintero R and Ferreira V M 2011 Coda wave attenuation in the Parecis Basin, Amazon Craton, Brazil: Sensitivity to basement depth; J. Seismol. 15 391-409.

Biswas K and Mandal P 2017 Modeling of source parameters and moment tensors of local earthquakes occurring in the Eastern Indian Shield; J. Geol. Soc. India 89 619-630, https://doi.org/10.1007/s12594-017-0671-2.

Biswas K, Kumar M and Mandal P 2016 Lapse time dependent coda-Q $\left(Q_{c}\right)$ in the Kachchh, rift zone, Gujarat, India; Nat. Hazards 81 1589-1610, https://doi.org/10. 1007/s11069-016-2147-x.

Chandra U 1977 Earthquakes of Peninsular India - A seismotectonic study; Bull. Seismol. Soc. Am. 67(5) 1387-1413.
Chetty T R K and Murthy D S N 1994 Regional tectonic framework of the Eastern Ghats Mobile Belt: A new interpretation; In: Proceedings of the workshop on Eastern Ghat Mobile Belt, Geol. Surv. Ind. 44 39-50.

Chung J, Chen Y and Shin T 2009 Spatial distribution of coda $Q$ estimated from local earthquakes in Taiwan area; Earth Planet. Space 611 1077-1088.

Dainty A M and Toksoz M N 1981 Seismic codas on the earth and the moon a comparison; Phys. Earth Planet. Inter. 26 250-260.

Dasovic I, Herak M and Herak D 2013 Coda- $Q$ and its lapse time dependence analysis in the interaction zone of the Dinarides, the Alps and the Pannonian basin; Phys. Chem. Earth 63 47-54.

Dunn J A 1929 The geology of north Singhbhum; Mem. Geol. Soc. India $\mathbf{5 4} 166$.

Fehler M, Hoshiba M, Sato H and Obara K 1992 Separation of scattering and intrinsic attenuation for the KantoTokai region, Japan, using measurements of S-wave energy versus hypocentral distance; Geophys. J. Int. 108 787800.

Frankel A D and Wennerberg L 1987 Energy-flux model of seismic coda: Separation of scattering and intrinsic attenuation; Bull. Seismol. Soc. Am. 771 223-1251.

Frankel A, Mcgarr A, Bicknell J, Mri J, Seeber L and Cranswick E 1990 Attenuation of high-frequency shear waves in the crust: Measurements from New York State, South Africa and Southern California; J. Geophys. Res. 95 17441-17457.

Gao L S, Lee L C, Biswas N N and Aki K 1983 Comparison of the effects between single and multiple scattering on Coda waves for local earthquakes; Bull. Seismol. Soc. Am. 73 377-389.

Ghosh S K and Sengupta S 1990 The Singhbhum shear zone: Structural transition and a kinematic model; Proc. Indian Acad. Sci. 1 229-247.

Giampiccolo E, Tusa G, Langer H and Gresta S 2002 Attenuation in Southeastern Sicily (Italy) by applying different coda methods; J. Seismol. 6 487-501.

Gupta S, Mohanty W K, Mandal A and Misra S 2014 Ancient terrane boundaries as probable seismic hazards: A case study from the northern boundary of the Eastern Ghats Belt, India; Geosci. Front. 5 17-24.

Gusev A A 1995 Vertical profile of turbidity and coda Q; Geophys. J. Int. 123 665-672.

Havskov J and Ottemoller L 2003 SEISAN: The earthquake analysis softwares for Windows, Solaris and Linux, Version 8.0; Institute of Solid Earth Physics, University of Bergen, Norway.

Havskov J, Malone S, Mcclurg D and Crosson R 1989 Coda $Q$ for the state of Washington; Bull. Seismol. Soc. Am. 79 1024-1038.

Havskov J, Sørensen M, Vales D, Özyazıcıŏlu M, Sánchez G and Li B 2016 Coda $Q$ in different tectonic areas, influence of processing parameters; Bull. Seismol. Soc. Am. 106(3) 956-970.

Hazarika P, Kumar M R and Kumar D 2013 Attenuation character of seismic waves in Sikkim Himalaya; Geophys. J. Int. 195 544-557.

Herak M 1991 Lapse time dependent $Q_{c}$-spectra observed in the Dinarides region (Yugoslavia); Phys. Earth Planet. Inter. 67 303-312. 
Herraiz M and Espinosa A F 1987 Coda waves: A review; Pure Appl. Geophys. 125 499-577.

Herrmann R B 1980 Q estimation using the coda of local earthquakes; Bull. Seismol. Soc. Am. 70 447-468.

Hoshiba M 1991 Simulation of multiple scattered coda wave excitations based on the energy conservation law; Phys. Earth Planet. Inter. 67 123-136.

Hoshiba M 1993 Separation of scattering attenuation and intrinsic absorption in Japan with the multiple lapse time window analysis from full seismogram envelope; J. Geophys. Res. 98(15) 809-824.

Jin A and Aki K 1988 Spatial and temporal correlation between coda $Q$ and seismicity in China; Bull. Seismol. Soc. Am. 78 741-769.

Kayal J R, Srivastava V K, Bhattacharya S N, Khan P $\mathrm{K}$ and Chatterjee R 2009 Source parameters and focal mechanisms of local earthquakes: Single broadband observatory at ISM Dhanbad; J. Geol. Soc. India 74 413419.

Khan P K, Biswas B, Samdarshi P and Prasad R 2011 Seismicity and the coda- $Q$ variation in eastern Indian shield region; Indian J. Geosci. 65(2) 43-50.

Khan P K, Bhukta K and Tarafder G 2016 Coda $Q$ in Eastern Indian Shield; Act. Geodt. Geophys. 51 333-346, https://doi.org/10.1007/s40328-015-0129.

Kopnichev Y F 1977 The role of multiple scattering in the formation of a seismogram's tail; Izv. Acad. Sci. USSR, Phy. Solid Earth 13 394-398.

Kvamme L B and Havskov J 1989 Q in Southern Norway; Bull. Seismol. Soc. Am. 79 1575-1588.

Mak S, Chan L S, Chandler A M and Koo R C H 2004 Coda $Q$ estimates in the Hong Kong region; J. Asian Earth Sci. 24 127-136.

Mandal P and Biswas K 2016 Teleseismic receiver function modeling of the eastern Indian craton; Phys. Earth Planet. Inter. 268 1-14, https://doi.org/10.1016/j.pepi.2016.07. 002.

Mandal P, Jainendra S, Joshi S, Kumar S, Bhunia R and Rastogi B K 2004 Low coda $Q_{c}$ in the epicentral region of the 2001 Bhuj earthquake of Mw 7.7; Pure Appl. Geophys. 161 1635-1654.

Margerin L, Campillo M and Van Tiggelen B 1998 Radiative transfer and diffusion of waves in a layered medium, new insight into coda $Q$; Geophys. J. Int. $134247-258$.

Mazumder R, Van Loon A J, Mallik L, Reddy S M, Arima M, Altermann W, Eriksson P G and De S 2012 Mesoarchaean-Palaeoproterozoic stratigraphic record of the Singhbhum crustal province, eastern India: A synthesis; In: Palaeoproterozoic of India (eds) Mazumder R and Saha D, Geol. Soc. London 365 31-49.

Misra S 2006 Precambrian chronostratigraphic growth of Singhbhum-Orissa Craton, Eastern Indian Shield: An alternative model; J. Geol. Soc. India 67 356-378.

Mitchell B J 1981 Regional variation and frequency dependence of $Q$ in the crust of the United States; Bull. Seismol. Soc. Am. 71 1531-1538.

Mitchell B 1995 Anelastic structure and evolution of the continental crust and upper mantle from seismic surface wave attenuation; Rev. Geophys. 33 441-462.

Mukhopadhyay S, Tyagi C and Rai S S 2006 The attenuation mechanism of seismic waves in northwestern Himalayas; Geophys. J. Int. 167 354-360.
Mukhopadhayay S and Tyagi C 2007 Lapse time and frequency-dependent attenuation characteristics of coda waves in the Northwestern Himalayas; J. Seismol. 11 149-158.

Mukhopadhyay J, Beukes N J, Armstrong R A, Zimmermann U, Ghosh G and Medda R A 2008 Dating the oldest Greenstone in India: A $3.51 \mathrm{Ga}$ precise U-Pb SHRIMP Zircon Age for Dacitic Lava of the Southern Iron Ore Group, Singhbhum Craton; J. Geol. 116 449-461.

Nuttli O W 1973 Seismic wave attenuation and magnitude relations for eastern North America; J. Geophys. Res. 78 876-885.

Oldham T 1883 A catalogue of Indian earthquakes from the earliest times to the end of 1869 A.D.; Mem. Geol. Surv. India 19(3) 163-215.

Padhy S 2009 Characteristics of body-wave attenuations in the Bhuj crust; Bull. Seismol. Soc. Am. 993300 3313.

Padhy S and Subhadra N 2010 Attenuation of high-frequency seismic waves in northeast India; Geophys. J. Int. 181 453-467.

Parvez I A, Sutar A K, Mridula M, Mishra S K and Rai S S 2008 Coda $Q$ estimates in the Andaman Islands using local earthquakes; Pure Appl. Geophys. 165 1861-1878.

Paul A, Gupta S C and Pant C 2003 Coda $Q$ estimates for Kumaun Himalaya; Proc. Indian Nat. Sci. Acad. (Earth Planet. Sci.) 112 569-576.

Pujades L, Ugalde A, Canas J A, Navarro M, Badal F J and Corchete V 1997 Intrinsic and scattering attenuation form observed seismic codas in the Almeria Basin (Southeastern Iberian Peninsula); Geophys. J. Int. 129 281-291.

Pulli J J 1984 Attenuation of coda waves in New England; Bull. Seismol. Soc. Am. 74 1149-1166.

Rautian T G and Khalturin V I 1978 The use of the coda for determination of earthquake source spectrum; Bull. Seismol. Soc. Am. 68 923-948.

Roecker S W, Tucker B, King J and Hatzfeld D 1982 Estimates of $Q$ in central Asia as a function of frequency and depth using the coda of locally recorded earthquakes; Bull. Seismol. Soc. Am. 72 129-149.

Saha A K 1994 Crustal evolution of Singhbhum - North Orissa, Eastern India; Mem. Geol. Soc. India 27341.

Sarkar A N 1982 Precambrian tectonic evolution of eastern India: A model of converging microplates; Tectonophys. 86 363-397.

Sarkar A N and Chakraborty D K 1982 One orogenic belt or two? A structural reinterpretation supported by Landsat data products of the Precambrian metamorphics of Singhbhum, Eastern India; Photogrammetria 37 185-201.

Sato H 1977 Energy propagation including scattering effects single isotropic scattering approximation; J. Geophys. Res. 25 27-41.

Sato H 1988 Fractal interpretation of the linear relation between logarithms of maximum amplitude and hypocentral distance; Geophys. Res. Lett. 15 373-375.

Sato H and Fehler M C 1998 Seismic wave propagation and scattering in the heterogeneous earth; Springer-Verlag, New York.

Sharma B, Gupta A K, Devi D K, Kumar D, Teotia S S and Rastogi B K 2008 Attenuation of high-frequency seismic waves in Kachchh Region, Gujarat, India; Bull. Seismol. Soc. Am. 98 2325-2340. 
Singh S and Hermann R 1983 Regionalization of crustal coda $Q$ in the continental United States; J. Geophys. Res. 88 $527-538$

Singh S K, Garcia D, Pacheco J F, Valenzuela R, Bansal B K and Dattatrayam R S 2004 Q of the Indian Shield; Bull. Seismol. Soc. Am. 94 1564-1570.

Tait J, Zimmermann U, Miyazaki T, Presnyakov S, Chang Q, Mukhopadhyay J and Sergeev S 2011 Possible juvenile Palaeoarchaean TTG magmatism in eastern India and its constraints for the evolution of the Singhbhum craton; Geol. Mag. 148 340-347.
Wu R S 1985 Multiple scattering and energy transfer of seismic waves: Separation of scattering effect from intrinsic attenuation - I. Theoretical modeling; Geophys. J. Roy. Astron. Soc. 82 57-80.

Yoshimoto K, Sato H and Ohtake M 1993 Frequencydependent attenuation of $\mathrm{P}$ and $\mathrm{S}$ waves in the Kanto area, Japan, based on the coda normalization method; Geophys. J. Int. 114 165-174.

Zeng Y, Su F and Aki K 1991 Scattered wave energy propagation in a random isotropic scattering medium: 1. Theory; J. Geophys. Res. 96 607-619.

Corresponding editor: ARKoprovo BiswaS 